\title{
A Novel Missense Mutation in the CLPP Gene Causing Perrault Syndrome Type 3 in a Turkish Family
}

\author{
Fatma Dursun1,*, Hussein Sheikh Ali Mohamoud2,3,*, Noreen Karim4, Muhammad Naeem4, \\ Musharraf Jelani2,5, Heves Kırmızıbekmez1 \\ 1 Ümraniye Training and Research Hospital, Clinic of Pediatric Endocrinology, Istanbul, Turkey \\ ${ }^{2}$ King Abdulaziz University, Princess Al-Jawhara Albrahim Centre of Excellence in Research of Hereditary Disorders, Jeddah, Saudi Arabia \\ 3St. George's University of London, Human Genetics Research Centre, Division of Biomedical Sciences, London, United Kingdom \\ ${ }^{4}$ Quaid-I-Azam University Faculty of Biological Sciences, Medical Genetics Research Laboratory, Department of Biotechnology, Islamabad, Pakistan \\ ${ }^{5}$ Khyber Medical University, Institute of Basic Medical Sciences, Department of Biochemistry, Medical Genetics and Molecular Biology Unit, \\ Peshawar, Pakistan \\ *These authors contributed equally to this work
}

\section{WHAT IS ALREADY KNOWN ON THIS TOPIC?}

Mutations in five genes -HSD I 7B4, HARS2, CLPP, LARS2, and ClOorf2- have been reported in five subtypes of Perrault syndrome.

\section{ABSTRACT}

Perrault syndrome (PRLTS) is a heterogeneous group of clinical and genetic disorders characterized by sensory neuronal hearing loss in both sexes and premature ovarian failure or infertility in females. Neurological and hearing loss symptoms appear early in life, but female infertility cannot be detected before puberty. Spastic limbs, muscle weakness, delayed puberty and irregular menstrual cycles have also been observed in PRLTS patients. Mutations in five genes, i.e. HSD17B4, HARS2, CLPP, LARS2, and C10orf2, have been reported in five subtypes of PRLTS. Here, we report a milder phenotype of PRLTS in a Turkish family in which two affected patients had no neurological findings. However, both were characterized by sensory neuronal hearing loss and the female sibling had secondary amenorrhea and gonadal dysgenesis. Genome-wide homozygosity mapping using 300K single-nucleotide polymorphism microarray analysis together with iScan platform (IIlumina, USA) followed by candidate gene Sanger sequencing with ABI 3500 Genetic Analyzer (Life Technologies, USA) were used for molecular diagnosis. We found a novel missense alteration c.624C>G; p.lle208Met in exon 5 of the CLPP at chromosome 19p13.3. This study expands the mutation spectrum of CLPP pathogenicity in PRLTS type 3 phenotype.

Keywords: Secondary amenorrhea, Perrault syndrome, CLPP

Conflict of interest: None declared

Received: 09.12.2015

Accepted: 05.04 .2016

\section{WHAT THIS STUDY ADDS?}

We found a novel missense alteration c.624C>G; p.lle208Met in exon 5 of the CLPP at chromosome 19p/3.3. This study expands the mutation spectrum of CLPP pathogenicity in Perrault syndrome type 3 phenotype.

\section{Address for Correspondence}

Heves Kırmızıbekmez MD, Ümraniye Training and Research Hospital, Clinic of Pediatric Endocrinology, Istanbul, Turkey

Phone: +90 2166321818 E-mail: heveskirmizibekmez@yahoo.com

(CJournal of Clinical Research in Pediatric Endocrinology, Published by Galenos Publishing. 


\section{Introduction}

Perrault syndrome (PRLTS) is a rare autosomal recessive disorder leading to pure gonadal dysgenesis in affected females $(46, X X)$ and sensorineural hearing loss (SNHL) or deafness in males. Ovarian dysfunction ranges from absent or streak gonads to primary ovarian insufficiency defined as cessation of menses before age 40 years (1). Central nervous system findings have also been reported with this syndrome. Neurologic features described in some affected women include developmental delay, intellectual disability, cerebellar ataxia, and motor and sensory peripheral neuropathy (1).

Pathogenic alterations in five genes have been reported in five subtypes of PRLTS. PRLTS type 1 is caused by mutations in HSD17B4 gene at chromosome 5q23.1 (2) and PRLTS1 patients may present with hearing loss, ovarian dysgenesis leading to female infertility, male infertility, ataxia, and peripheral neuropathy $(2,3,4)$. PRLTS type 2 is caused by mutations in HARS2 at chromosome $5 \mathrm{q} 31.3$ and is characterized by deafness in both males and females and gonadal dysgenesis in female patients only (5). PRLTS type 3 is caused by mutations in CLPP gene at chromosome 19p13.3 $(6,7)$. PRLTS3 patients may present with progressive hearing loss, female infertility and premature menopause, microcephaly, epilepsy, growth and mental retardation $(6,7)$. PRLTS type 4 is caused by mutations in LARS2 gene at chromosome 3p21.31and is characterized by hearing loss and premature ovarian failure (8). PRLTS type 5 is caused by mutations in C10orf2 gene at chromosome 10q24.31 (9). PRLTS5 patients may present with progressive ataxia, axonal neuropathy, hyporeflexia, abnormal eye movements, progressive hearing loss, and ovarian dysgenesis (9).

Here, we report the clinical and molecular investigations of two PRLTS patients from a Turkish family (Figure 1).

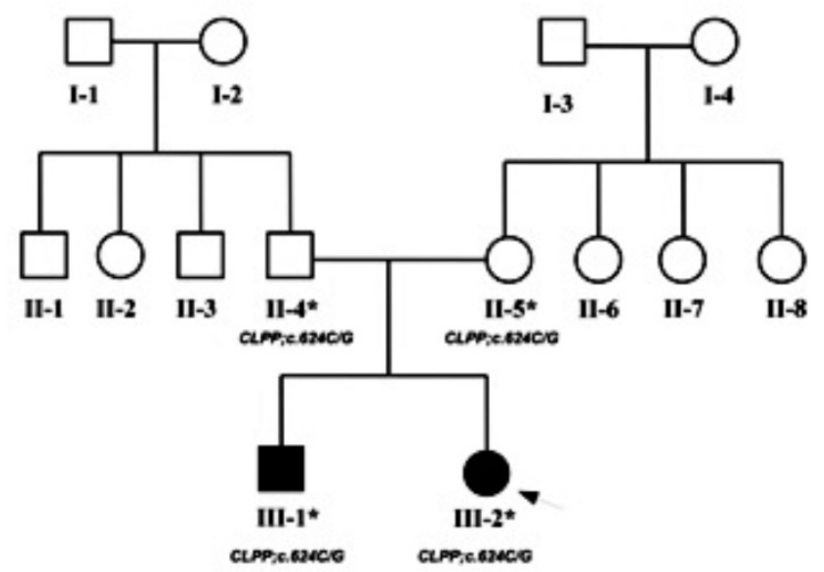

Figure 1. Pedigree of the parents showing autosomal recessive mode of inheritance in the affected individuals. The index patient is indicated with an arrow. The asterisk $\left(^{*}\right)$ indicates the samples that were validated by Sanger sequencing with their respective genotypes below each symbol

\section{Case Reports}

\section{Patient 1}

The patient was a 16-year-old girl (III-2) who presented with secondary amenorrhea. She was attending a special school for hearing-impaired students. The parents were both healthy and non-consanguineous but came from the same village. There were no dysmorphic findings or evidence of other systemic disease in the physical examination. Her weight was 51 kg (25p), height was $160 \mathrm{~cm}$ (25-50p), axillary hair was present, pubic hair was at stage 5 , and breast development was bilaterally at stage 3 according to the Tanner staging. Neurologic examination was normal. Pelvic ultrasonography revealed a uterus of $8 \times 12 \times 50$ $\mathrm{mm}$ in size, but ovaries could not be detected. Whole blood count, renal functions, liver functions, as well as glucose and electrolyte levels were within normal ranges, while hormone studies revealed hypergonadotropic hypogonadism. Luteinizing hormone was $20.7 \mathrm{mlU} / \mathrm{mL}$, follicle stimulating hormone was $63.8 \mathrm{mlU} / \mathrm{mL}$, and estradiol was $15 \mathrm{pg} / \mathrm{mL}$. The karyotype was $46, X X$. Adrenal steroid levels and thyroid functions were also normal. Hormone replacement treatment with estrogen was initiated. The patient was suspected to have PRLTS because of gonadal failure in association with bilateral sensorineural deafness. Repeated neurologic examination was normal as well as the brain magnetic resonance imaging.

\section{Patient 2}

He was the 21-year-old brother (III-1) of our first patient. He was invited to the clinic because of his hearing loss and a sibling with the clinical diagnosis of PRLTS. He had also attended a school for hearing-impaired students. Physical examination revealed no dysmorphic findings. He was in Tanner stage 5 of puberty with a height and weight of $170 \mathrm{~cm}$ [-0.95 standard deviation score (SDS)] and $75 \mathrm{~kg}$ (+0.36 SDS), respectively. Neurologic examination was normal. However, he was under the supervision of a psychiatrist and receiving risperidone because of attention-deficit disorder.

\section{Genetic Analysis}

\section{Homozygosity Mapping}

Genome-wide homozygosity mapping on four family members (unaffected parents and the two affected siblings) was performed using 300K single-nucleotide polymorphism (SNP) microarray (HumanCytoSNP12.2 chip) along with iScan platform (Illumina, USA). We found that a region on 19p13.3 was homozygous in the two affected individuals and was heterozygous in the two parents (Figure 2). This $2 \mathrm{Mb}$ region (chr19:5469832-7472041) contained 64 genes including CLPP according to human genome map (Annotation release 105 http://www.ncbi.nlm.nih.gov/projects/mapview/) 


\section{Sanger Sequencing}

Genomic sequence of the wild-type CLPP gene (ENSG00000125656) was obtained from Ensembl Genome Browser (www.ensembl.org). The six coding exons including exon-intron boundaries were polymerase chain reaction amplified with the primers sets (in Table 1) and sequenced with ABI3500 Genetic Analyzer according the manufacturer's instructions (Life Technologies, USA). We found a novel homozygous transversion alteration, cytosine to guanine, in exon 5 at nucleotide 624 (c.624C>G) of CLPP gene causing alteration of isoleucine to methionine at 208 amino acid position

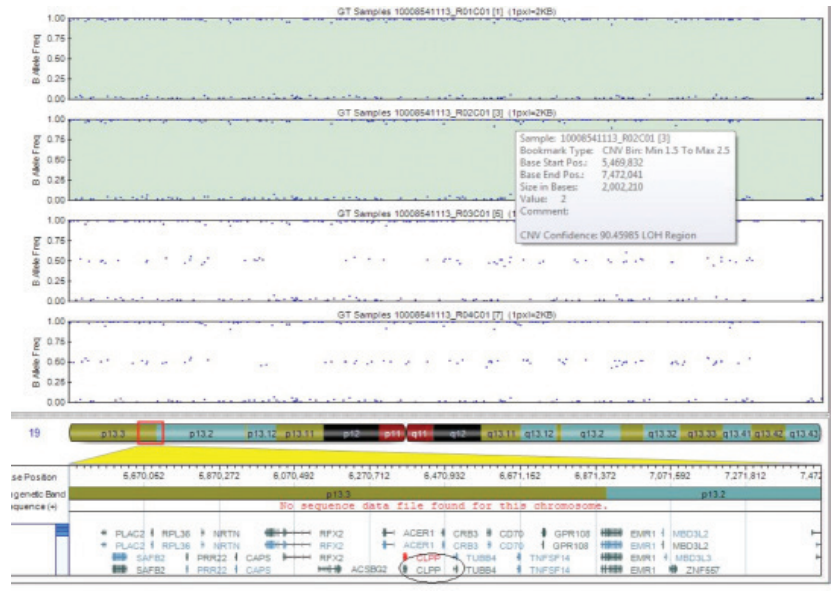

Figure 2. Single-nucleotide polymorphism microarray analysis showing a common region of homozygosity in the affected individuals flanking CLPP gene on chromosome 19p13.3

\section{A}

AAGCAGC T TATAACATG TACGCCAAGCACACCAA $\downarrow$

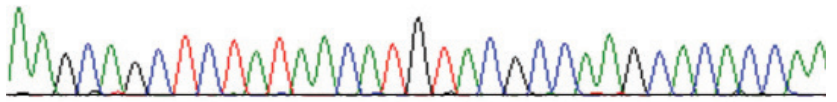
B

A.AGAGCTCTATAACATCTACGCCAAGCACAC CAA $\downarrow$

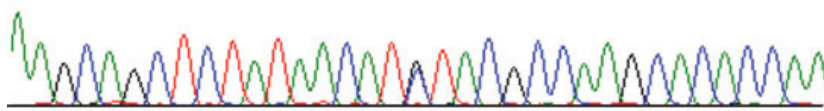

C

AAGCAGC TC TATAACATC TACG C CAAG CACACCAA

$\downarrow$

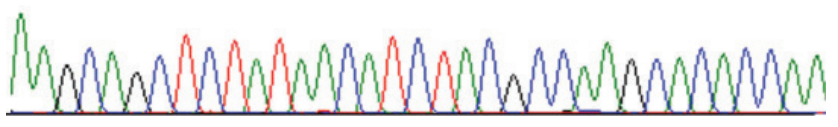

Figure 3. Sequencing analysis of the CLPP gene exon 5 showing $C$ to $\mathrm{G}$ transversion at nucleotide position 624 (c.624C $>\mathrm{G}$ ) in the affected patients (A), heterozygous carrier parents (B), and unaffected siblings or healthy controls $(\mathrm{C})$
(p.lle208Met). Both parents were heterozygous (carriers) for this variant confirming the autosomal recessive inheritance of PRLTS3 phenotype in this family (Figure 3). Sequencing of 100 unaffected healthy individuals (200 chromosomes) excluded the probability of neutral polymorphism of the variant (CLPP; c.624C>G) identified in our patients. Computational prediction software (SIFT, Polyphen-2 and Mutation Taster) declared this alteration as protein damaging. Furthermore, this variant (chr19:6366337C>G) had not been listed in 1000 human genome (http://browser.1000genomes.org/) in 60,706 individuals in the Exome Aggregation Consortium (http://exac. broadinstitute.org// databases.

\section{Discussion}

Genetic analysis of PRLTS remained unresolved until the first gene was discovered in 2010 (2). Since then, several familial and sporadic cases have been reported, of which, the majority was of European descent $(2,5,8)$. PRLTS3 gene was identified in three Pakistani families (6) and we also screened a family from Saudi Arabia very recently (7). To date, only four mutations including one splicing (c.270+A>G) and three missense (c.433A>C; p.Thr145Pro, c.440G>C; p.Cys147Ser, c.685T>G; p.Tyr229Asp) have been identified in the CLPP gene $(6,7)$. Here, we present, for the first time, a novel CLPP alteration in a Turkish family.

Table 1. List of primers along with the annealing temperature used for polymerase chain reaction amplification of the six coding exons of CLPP gene

\begin{tabular}{|l|l|l|l|}
\hline No & Primer name & Primer sequence (5'-3') & Annealing \\
\hline 1 & CLPP_1-2F & GGACTCGAACTGGAGACTCTAAA & $62.9^{\circ} \mathrm{C}$ \\
\hline 2 & CLPP_1-2R & TTAAGAGCCGAGGAGCAGAG & $60.5^{\circ} \mathrm{C}$ \\
\hline 3 & CLPP_3F & CTTCCTGGTTCCCTGACC C & $61.7^{\circ} \mathrm{C}$ \\
\hline 4 & CLPP_3R & ACGCTCTGCACCCTTTCCCA & $62.5^{\circ} \mathrm{C}$ \\
\hline 5 & CLPP_4F & CCAGGTTTAGGAGATGGAAT & $56.4^{\circ} \mathrm{C}$ \\
\hline 6 & CLPP_4R & TGTCTAGACCCTGTCCTGAT & $58.4^{\circ} \mathrm{C}$ \\
\hline 7 & CLPP_5F & AGCCCACCAGCCTCAAAC & $58.4^{\circ} \mathrm{C}$ \\
\hline 8 & CLPP_5R & CATCCCAGAGAACGATCCAG & $60.5^{\circ} \mathrm{C}$ \\
\hline 9 & CLPP_5R2 & GCCCTGAAAGTCCGCAGGG & $63.0^{\circ} \mathrm{C}$ \\
\hline 10 & CLPP_6F2 & GACCCAGACCTGGCCCTG & $63.0^{\circ} \mathrm{C}$ \\
\hline 11 & CLPP_6R2 & TCCAAGCCCAGCAACAAGGG & $62.5^{\circ} \mathrm{C}$ \\
\hline 12 & CLPP_6R3 & CCACATGATTCTGGAGAGGAG & $61.3^{\circ} \mathrm{C}$ \\
\hline
\end{tabular}


Dursun F et al.

Perrault Syndrome-Type 3

The CLPP enzyme is a 277 amino acid-long peptidase which works in the presence of ATP and magnesium cleaving of larger proteins to smaller peptides $(10,11,12)$. Accumulation of CLPX, mtDNA, and inflammatory factors in tissues have been observed in mice mutants due to CLLP loss of function leading to infertility, hearing loss, and growth retardation (13). A similar mechanism might be involved in humans with PRLTS3 carrying CLPP alterations $(6,7)$.

Molecular diagnosis of PRLTS is efficiently performed through genome-wide SNP microarray for linkage analysis followed by candidate gene sequencing or by directly stepping into whole exome sequencing. These methods can either be utilized individually $(2,5,6,8,9)$ or by combing the two strategies (7). Exome analysis has the advantage of finding causative variants more efficiently compared to candidate gene screening in rare genetic disorders $(14,15)$. However, genome-wide SNP microarray genotyping or array comparative genomic hybridization (CGH) has the advantage of finding out the chromosomal aberrations (16), which may not be possible through whole exome analysis alone. The SNP microarray can also exclude known PRTLS candidates to pin point a single region of homozygosity in ethnically isolated populations $(6,17)$. Here, we found the genome-wide SNP microarray analysis followed by candidate (CLPP) gene sequencing as a successful strategy for identifying the causative variant underlying PRLTS3 in an isolated Turkish family.

In the clinical diagnosis of PRLTS, SNHL and neurological abnormalities both in males and females and female ovarian dysgenesis are considered key findings $(1,18)$. Amenorrhea, gonadal dysgenesis, and SNHL were present in our index patient. However, all these signs may not be detected in younger patients (7). For example, patients with ovarian failure may present with lack of female sexual characteristics, or with primary or secondary amenorrhea. In such cases, pathogenic variants in various causative genes involved in ovarian dysgenesis could be of help in precise diagnosis $(19,20)$. Autoimmunity is also considered as one of the important exclusion factors in patients with ovarian insufficiency, especially in secondary amenorrhea cases $(21,22)$. Congenital disorders of adrenal and gonadal steroidogenesis are also rare causes of ovarian failure (23). Similarly, hearing loss is reported to be present in approximately $50 \%$ of women with Turner syndrome (18). For this reason, girls with delayed puberty or amenorrhea with low estrogen and raised gonadotropins need to be investigated either by karyotyping or array CGH analysis to exclude abnormalities of the X chromosome $(20,24,25,26)$.

In addition to SNHL and ovarian insufficiency, neuromuscular abnormalities (spastic diplegia, dysarthria, titubation of the head, hyporeflexia, sensory neuropathy, demyelinating polyneuropathy, cerebellar ataxia, nystagmus, ophthalmoplegia, ptosis, seizures), developmental abnormalities (microcephaly, delayed motor and mental development, learning disabilities), and dysmorphic findings (pes cavus, pes equinovarus, contracted heel cords, atypical facial features, short neck) were found to be associated with PRLTS1 $(2,3,27,28,29)$. These features were not observed in our cases. Previously, we and others reported that short stature, microcephaly, seizures, moderate learning difficulties, and truncal and cerebellar ataxia with signs of lower limb spasticity may occur in PRLTS3 $(6,7)$. Neurologic disabilities, which started by the 18th month and worsened through years, were defined in two siblings with a CLPP mutation in Pakistani and Saudi families (8), but were not observed in our patients. The PRLTS5 patients are also characterized by progressive ataxia, axonal neuropathy, hyporeflexia, and abnormal eye movements as previously reported in Japanese patients (9), but these symptoms were also not observed in our cases.

Our primary clinical diagnosis in our patients, due to absence of neurological findings, pointed to either PRTLS2 or PRLTS4. However, after establishing the molecular diagnosis of CLPP pathogenicity, we concluded that p.lle208M might have caused a milder PRLTS3 phenotype in our cases. On the other hand, it must be remembered that all the features may not always be prominent in PRLTS3 patients. For example, a previously reported Pakistani family, with splice donor-site mutation (c.270+A $>G$ in CLPP), had only hearing loss with neither brain involvement nor any other associated abnormality (6). The clinical features of PRLTS3 are also age-dependent as described previously (7). Furthermore, we assume that hearing defect and ovarian dysgenesis without neurological findings might be a specific association with our mutation. Marlin et al (30) reviewed 34 cases from 15 families and reported hearing defect and ovarian dysgenesis without neurological findings. Our analyses encourage CLPP screening in such cases.

In conclusion, PRLTS is clinically diagnosed with the presence of primary ovarian failure in association with $\mathrm{SNHL}$, and sometimes, with neuromuscular involvement. Clinical presentation is quite variable since the onset of all components may take time to appear. Gonadal insufficiency is not usual in boys and is noted only after pubertal age in girls. For these reasons, this syndrome should be suspected in patients presenting with unexplained neurologic findings and SNHL. The definite diagnosis of the type of PRLTS can be made only by molecular analyses since the clinical features may overlap. Patients with an identified mutation in the genes associated with PRLTS should be followed up in terms of clinical findings even if they are asymptomatic. Our patients were unique for having a novel mutation in CLPP gene, which leads to a mild form of PRLTS3 without any neurologic involvement. The genome-wide SNP microarray genotyping or array $\mathrm{CGH}$ followed by candidate gene sequencing may be used as a useful tool for PRTLS-causative variant identification in ethnically or geographically isolated familial cases.

\section{Acknowledgments}

The authors, therefore, acknowledge with thanks DSR for technical and financial support. Noreen Karim was supported by an indigenous PhD fellowship from HEC, Islamabad, Pakistan. 


\section{Ethics}

Informed Consent: It was taken.

Peer-review: Externally peer-reviewed.

\section{Authors Contributions}

Concept: Fatma Dursun, Musharraf Jelani, Heves Kırmızıbekmez, Design: Musharraf Jelani, Fatma Dursun, Hussein Sheikh Ali Mohammoud, Data Collection and Processing: Hussein Sheikh Ali Mohammoud, Noreen Karim, Analysis and Interpretation: Noreen Karim, Muhammad Naeem, Literature Research: Muhammed Naeem, Heves Kırmızıbekmez, Writing: Musharraf Jelani, Fatma Dursun, Heves Kırmızıbekmez.

Financial Disclosure: This project was funded by the Deanship of Scientific Research (DSR), King Abdulaziz University, Jeddah, under grant no. (1-287/1433/HiCi).

\section{References}

1. Newman WG, Friedman TB, Conway GS. Perrault Syndrome. In: Pagon RA, Adam MP, Ardinger HH (eds). Gene Reviews(R). Seattle WA: University of Washington, Seattle, 1993.

2. Pierce SB, Walsh T, Chisholm KM, Lee MK, Thornton AM, Fiumara A, Opitz JM, Levy-Lahad E, Klevit RE, King MC. Mutations in the DBPdeficiency protein HSD17B4 cause ovarian dysgenesis, hearing loss, and ataxia of Perrault Syndrome. Am J Hum Genet 2010;87:282-288. Epub 2010 Jul 30

3. McMillan HJ, Worthylake T, Schwartzentruber J, Gottlieb CC, Lawrence SE, Mackenzie A, Beaulieu CL, Mooyer PA, Consortium FC, Wanders RJ, Majewski J, Bulman DE, Geraghty MT, Ferdinandusse S, Boycott KM. Specific combination of compound heterozygous mutations in 17beta-hydroxysteroid dehydrogenase type 4 (HSD17B4) defines a new subtype of D-bifunctional protein deficiency. Orphanet J Rare Dis 2012;7:90.

4. Konkolova J, Petrovic R, Chandoga J, Repisky M, Zelinkova $H$, Krsiakova J, Kolnikova M, Kantarska D, Sutovsky S, Bohmer D. Peroxisomal D-bifunctional protein deficiency: First case reports from Slovakia. Gene 2015;568:61-68. Epub 2015 May 9

5. Pierce SB, Chisholm KM, Lynch ED, Lee MK, Walsh T, Opitz JM, Li W, Klevit RE, King MC. Mutations in mitochondrial histidyl tRNA synthetase HARS2 cause ovarian dysgenesis and sensorineural hearing loss of Perrault syndrome. Proc Natl Acad Sci U S A 2011;108:6543-6548. Epub 2011 Apr 4

6. Jenkinson EM, Rehman AU, Walsh T, Clayton-Smith J, Lee K, Morell RJ, Drummond MC, Khan SN, Naeem MA, Rauf B, Billington $N$, Schultz JM, Urquhart JE, Lee MK, Berry A, Hanley NA, Mehta S, Cilliers D, Clayton PE, Kingston H, Smith MJ, Warner TT, University of Washington Center for Mendelian G, Black GC, Trump D, Davis JR, Ahmad W, Leal SM, Riazuddin S, King MC, Friedman TB, Newman WG. Perrault syndrome is caused by recessive mutations in CLPP, encoding a mitochondrial ATP-dependent chambered protease. Am J Hum Genet 2013;92:605-613. Epub 2013 Mar 28

7. Ahmed $S$, Jelani $M$, Alrayes $N$, Mohamoud HS, Almramhi MM, Anshasi W, Ahmed NA, Wang J, Nasir J, Al-Aama JY. Exome analysis identified a novel missense mutation in the CLPP gene in a consanguineous Saudi family expanding the clinical spectrum of Perrault Syndrome type-3. J Neurol Sci 2015;353:149-154. Epub 2015 May 1
8. Pierce SB, Gersak K, Michaelson-Cohen R, Walsh T, Lee MK, Malach $D$, Klevit RE, King MC, Levy-Lahad E. Mutations in LARS2, encoding mitochondrial leucyl-tRNA synthetase, lead to premature ovarian failure and hearing loss in Perrault syndrome. Am J Hum Genet 2013;92:614-620. Epub 2013 Mar 28

9. Morino $H$, Pierce $S B$, Matsuda $Y$, Walsh $T$, Ohsawa R, Newby M, Hiraki-Kamon K, Kuramochi M, Lee MK, Klevit RE, Martin A, Maruyama H, King MC, Kawakami H. Mutations in Twinkle primasehelicase cause Perrault syndrome with neurologic features. Neurology 2014:83:2054-2061. Epub 2014 Oct 29

10. Kang SG, Ortega J, Singh SK, Wang N, Huang NN, Steven AC, Maurizi MR. Functional proteolytic complexes of the human mitochondrial ATP-dependent protease, hClpXP. J Biol Chem 2002;277:2109521102. Epub 2002 Mar 28

11. Kang SG, Maurizi MR, Thompson M, Mueser T, Ahvazi B. Crystallography and mutagenesis point to an essential role for the $\mathrm{N}$-terminus of human mitochondrial ClpP. J Struct Biol 2004;148:338352.

12. Wang J, Hartling JA, Flanagan JM. The structure of ClpP at 2.3 A resolution suggests a model for ATP-dependent proteolysis. Cell 1997:91:447-456

13. Gispert $S$, Parganlija $D$, Klinkenberg $M$, Drose $S$, Wittig I, Mittelbronn M, Grzmil P, Koob S, Hamann A, Walter M, Buchel F, Adler T, Hrabe de Angelis M, Busch DH, Zell A, Reichert AS, Brandt U, Osiewacz $H D$, Jendrach $M$, Auburger $G$. Loss of mitochondrial peptidase Clpp leads to infertility, hearing loss plus growth retardation via accumulation of CLPX, mtDNA and inflammatory factors. Hum Mol Genet 2013;22:4871-4887. Epub 2013 Jul 12

14. Morris-Rosendahl DJ, Kaindl AM. What next-generation sequencing (NGS) technology has enabled us to learn about primary autosomal recessive microcephaly (MCPH). Mol Cell Probes 2015;29:271-281. Epub 2015 Jun 4

15. Sawyer SL, Hartley T, Dyment DA, Beaulieu $C L$, Schwartzentruber J, Smith A, Bedford HM, Bernard G, Bernier FP, Brais B, Bulman DE, Warman Chardon J, Chitayat D, Deladoey J, Fernandez BA, Frosk $P_{\text {, }}$ Geraghty MT, Gerull B, Gibson W, Gow RM, Graham GE, Green JS, Heon E, Horvath G, Innes AM, Jabado N, Kim RH, Koenekoop RK, Khan A, Lehmann OJ, Mendoza-Londono R, Michaud JL, Nikkel SM, Penney LS, Polychronakos C, Richer J, Rouleau GA, Samuels ME, Siu VM, Suchowersky O, Tarnopolsky MA, Yoon G, Zahir FR, Consortium FC, Care4Rare Canada C, Majewski J, Boycott KM. Utility of wholeexome sequencing for those near the end of the diagnostic odyssey: time to address gaps in care. Clin Genet 2016;89:275-284. Epub 2015 Sep 22

16. Gaboon NE, Jelani M, Almramhi MM, Mohamoud HS, Al-Aama JY. Case of Sjogren-Larsson syndrome with a large deletion in the ALDH3A2 gene confirmed by single nucleotide polymorphism array analysis. J Dermatol 2015;42:706-709. Epub 2015 Apr 9

17. Jelani M, Ahmed S, Almramhi MM, Mohamoud HS, Bakur K, Anshasi W, Wang J, Al-Aama JY. Novel nonsense mutation in the PTRF gene underlies congenital generalized lipodystrophy in a consanguineous Saudi family. Eur J Med Genet 2015;58:216-221. Epub 2015 Feb 23

18. Perrault M, Klotz B, Housset E. [Two cases of Turner syndrome with deaf-mutism in two sisters]. Bull Mem Soc Med Hop Paris 1951;67:79-84.

19. Guercio G, Costanzo M, Grinspon RP, Rey RA. Fertility Issues in Disorders of Sex Development. Endocrinol Metab Clin North Am 2015;44:867-881. Epub 2015 Sep 3

20. Fortuno C, Labarta E. Genetics of primary ovarian insufficiency: a review. J Assist Reprod Genet 2014;31:1573-1585. Epub 2014 Sep 18 
Dursun $\mathrm{F}$ et al.

Perrault Syndrome-Type 3

21. Dragojevic-Dikic S, Marisavljevic D, Mitrovic A, Dikic S, Jovanovic T, Jankovic-Raznatovic S. An immunological insight into premature ovarian failure (POF). Autoimmun Rev 2010;9:771-774. Epub 2010 Jun 26

22. Silva CA, Yamakami LY, Aikawa NE, Araujo DB, Carvalho JF, Bonfa E. Autoimmune primary ovarian insufficiency. Autoimmun Rev 2014;13:427-430. Epub 2014 Jan 10

23. Kim SM, Rhee JH. A case of 17 alpha-hydroxylase deficiency. Clin Exp Reprod Med 2015;42:72-76. Epub 2015 Jun 30

24. Pouresmaeili F, Fazeli Z. Premature ovarian failure: a critical condition in the reproductive potential with various genetic causes. Int J Fertil Steril 2014;8:1-12. Epub 2014 Mar 9

25. Artini PG, Ruggiero M, Papini F, Valentino V, Uccelli A, Cela V, Genazzani AR. Chromosomal abnormalities in women with premature ovarian failure. Gynecol Endocrinol 2010;26:717-724.

26. Qin $Y$, Jiao $X$, Simpson JL, Chen ZJ. Genetics of primary ovarian insufficiency: new developments and opportunities. Hum Reprod Update 2015;21:787-808. Epub 2015 Aug 4
27. Lines MA, Jobling R, Brady L, Marshall CR, Scherer SW, Rodriguez $A R$, Lee $L$, Lang $A E$, Mestre $T A$, Wanders RJ, Ferdinandusse $S$, Tarnopolsky MA, Canadian Pediatric Genetic Disorders Sequencing C. Peroxisomal D-bifunctional protein deficiency: three adults diagnosed by whole-exome sequencing. Neurology 2014;82:963-968. Epub 2014 Feb 19

28. Lieber DS, Hershman SG, Slate NG, Calvo SE, Sims KB, Schmahmann $J D$, Mootha VK. Next generation sequencing with copy number variant detection expands the phenotypic spectrum of HSD17B4deficiency. BMC Med Genet 2014;15:30.

29. Nascimento J, Mota C, Lacerda L, Pacheco S, Chorao R, Martins E, Garrido C. D-bifunctional protein deficiency: a cause of neonatal onset seizures and hypotonia. Pediatr Neurol 2015;52:539-543. Epub 2015 Jan 24

30. Marlin S, Lacombe D, Jonard L, Leboulanger N, Bonneau D, Goizet C, de Villemeur TB, Cabrol S, Houang M, Moatti L, Feldmann $D_{\text {, }}$ Denoyelle F. Perrault syndrome: report of four new cases, review and exclusion of candidate genes. Am J Med Genet A 2008;146A:661664. 